\title{
Drag Coefficient during Strong Typhoons
}

\author{
Binglan Wang, ${ }^{1}$ Lili Song, ${ }^{1}$ and Wenchao Chen ${ }^{2}$ \\ ${ }^{1}$ Public Meteorological Service Center, China Meteorological Administration, Beijing 100081, China \\ ${ }^{2}$ Guangdong Climate Centre, Guangzhou, Guangdong 510080, China
}

Correspondence should be addressed to Binglan Wang; wangbl@cma.gov.cn

Received 7 March 2013; Revised 13 May 2013; Accepted 21 May 2013

Academic Editor: Lian Xie

Copyright (C) 2013 Binglan Wang et al. This is an open access article distributed under the Creative Commons Attribution License, which permits unrestricted use, distribution, and reproduction in any medium, provided the original work is properly cited.

\begin{abstract}
Using data from wind towers during typhoons Hagupit and Nuri, drag coefficient was estimated. The relationship between drag coefficient and atmospheric stability was examined. The results indicate that the drag coefficient decreased when atmosphere stability changed from weakly stable or unstable to neutral. Relationship between drag coefficient and wind speed was also examined, and the results indicate that the relationships between drag coefficient and wind speed were similar to other researchers' result, but the wind thresholds were different due to different observation sites. Quantitative expressions between drag coefficient and wind speed were derived.
\end{abstract}

\section{Introduction}

Drag coefficient, an important factor to parameterize the wind stress on the sea surface, is widely used in modeling both atmospheric and oceanic dynamics, remote sensing, and other applications. In order to simulate the exact sea surface condition, accurate estimation of drag coefficient is urgently needed. Owing to the complicated water-air interaction on the sea surface, present parameterizations of the wind stress, or equivalently the drag coefficient, over the sea are far from satisfactory [1]. To help resolve this dilemma, there have been many attempts to estimate the drag coefficient. Geernaert et al. [2] reported on the behavior of the drag coefficient in relation to sea state during moderate to high wind speeds based on data collected over a water column depth of $15 \mathrm{~m}$. Rao [3] compared drag coefficient in two different sites using MONTBLEX-90 data. Grachev et al. [4] derived a a new formulation for the neutral drag coefficient in the convective boundary layer, based on the idea that free convection can be considered as a particular case of forced convection. Mahrt et al. [5] examined the dependence of the surface drag coefficient on stability, wind speed, mesoscale modulation of the turbulent flux using data sets collected over grassland, sparse grass, heather, and two forest sites.

Drag coefficients under tropical cyclones have been examined. Powell et al. [6] presented that the drag coefficient levels off and starts to decrease with a further increase in the wind speed at wind speeds increasing above hurricane values of about $33 \mathrm{~m} / \mathrm{s}$, which is contrary to the behavior of the drag coefficient parameterizations that are currently used in ocean and atmosphere applications. Moon et al. [7] found that the drag coefficient increased with wind speed at lower winds, but the rate of its increase was significantly reduced at high winds and there was a leveling off or even decrease in certain sectors. Makin [8] predicted the reduction of the drag coefficient for the wind speed exceeding hurricane values of $30-40 \mathrm{~m} / \mathrm{s}$ in agreement with field data according to a resistance law of the sea surface at hurricane winds.

In order to determine drag coefficient on the sea surface and provide a reference for modeling of typhoon, drag coefficients estimated from the turbulence measurements during typhoons Hagupit and Nuri were analyzed. The main aim of the present paper is to estimate the relationship between drag coefficient and wind speed during typhoon using experimental data.

\section{Analytical Data Description and Data Quality Control}

2.1. Data Description. Two typhoon cases were selected. Song et al. [9] presented two criteria according to the eddy structure of typhoon and the Beaufort scale of strong typhoon 
wind. (i) The wind direction with wind speed exceeding 8th grade Beaufort scale (10 min mean wind speed of 8 th grade is $17.2 \mathrm{~m} / \mathrm{s}$ ) successively alters over $120^{\circ}$. (ii) The variation of wind speed with time shows an " $M$ " shape during the passage of typhoons and if a low wind speed less than $11 \mathrm{~m} / \mathrm{s}$ occurs between two peak values, it can be judged as the typhoon eye area. The two criteria should be fulfilled at the same time to prove whether the typhoon center has passed over the observation site. According to the two criteria, two cases were selected to analyze drag coefficient during strong typhoons: typhoon Nuri (observed from Sanjiao Island) and typhoon Hagupit (observed from Zhizai Island). Both of the two selected typhoon observations captured the passage of typhoon's eye wall and eye, and this representative observation is called typical typhoon [10]. The typhoon tracks and the positions of the observation sites, Sanjiao Island (where typhoon Nuri was observed) and Zhizai Island (where typhoon Hagupit was observed), are showed in Figure 1 and Table 1.

Typhoon Nuri made landfall in the coastal region of the Sai Kung Sea in Hong Kong at 04:55 pm on 22nd Aug 2008 (Beijing time, hereinafter the same). The center of typhoon Nuri passed the tower located in Sanjiao Island at 18:50 on August 22, 2008, and the shortest distance from Sanjiao Island to typhoon center is about $32 \mathrm{~km}$. Data from Sanjiao Island during typhoon Nuri were collected. Sanjiao Island is located on the sea. The distance between northeastern coast of Macao and the island is about $12 \mathrm{~km}$ (Figure 1). The surface was covered by grass and bushes (Figure 2(a)). The wind tower was installed on a 93-meter high hill and was equipped by ultrasonic anemometers at the height of $10 \mathrm{~m}$ and $60 \mathrm{~m}$. The sonic data from 00:00 am on August 22 to 23:59 pm on August 23, 2008, were chosen to calculate drag coefficient and other parameters. Drag coefficient, mean wind speed, wind direction, and turbulence statistics have been calculated for period of $10 \mathrm{~min}$, and so there are 288 samples of typhoon Nuri observations.

Strong typhoon Hagupit made landfall in the coastal region of Chencun Town, Dianbai County, Maoming, Guangdong Province, at 06:45 am on September 24, 2008. The center of typhoon Hagupit passed the tower located in Zhizai Island at 05:10 on September 24, 2008, and the shortest distance from Zhizai Island to typhoon center is about $8.5 \mathrm{~km}$. In this paper, data from Zhizai Island during typhoon Hagupit were collected. The wind tower was installed on a 10-meter high hill on Zhizai Island which is located on the sea. The shortest distance between the $100 \mathrm{~m}$ high observation tower sites at Zhizai Island and the coast is $4.5 \mathrm{~km}$ (Figure 1). The surface was covered by sand and sparse weed. The terrain situation is illustrated in Figure 2(b). An ultrasonic anemometer was placed at the height of $60 \mathrm{~m}$. High frequency $(10 \mathrm{~Hz})$ observations of turbulence and the virtual temperature were obtained from the ultrasonic anemometer. The sonic data from 0:00 am to 23:59 pm on September 24, 2008, were chosen to calculate drag coefficient and other parameters. Turbulence statistics have been calculated for period of $10 \mathrm{~min}$, and so there are 144 samples of typhoon Nuri observation. The wind data from the observation tower were classified into "onshore wind" and "offshore wind," and detailed information of the two typhoon observations is showed in Table 1. Considering the complex surface of alongshore direction, along winds were not analyzed in this work.

2.2. Data Quality Control. Before analyzing, all the data were preprocessed as follows [11].

(1) Find the turbulence data spikes. Referring to Højstrup's [12] and Vickers and Mahrt's [13] methods, data satisfying the following formula can be considered as spikes:

$$
|d x(i)| \geq 4 \sigma
$$

where $x$ is the series of $u, v, w, d x(i)=x(i+1)-x(i)$ and $\sigma$ is the standard deviation of series $x$.

(2) Remove and interpolate the spikes by Højstrup's [12] method:

$$
x(i)=x(i-1) R_{m}+\left(1-R_{m}\right) X_{m}
$$

where $m$ is a constant ( $m=10$ in this paper), $R_{m}$ is the correlation coefficient between the series $x(i-m$ : $i-3)$ and $x(i-m+2: i-1)$, and $X_{m}$ is the mean value of the series $x(i-m: i-1)$.

\section{Analysis and Results}

3.1. Wind Characteristics. Using data from the ultrasonic anemometers on the wind tower located in Sanjiao Island, wind speed and direction during typhoon Nuri were calculated and are showen in Figures 3(a) and 3(b). At $60 \mathrm{~m}$ height, the maximum wind speed was $32.7 \mathrm{~m} / \mathrm{s}$, and the minimum wind velocity was $15.0 \mathrm{~m} / \mathrm{s}$. The significant "M-" shaped bimodal distribution was also found. The wind direction altered more than $120^{\circ}$ counterclockwise. Compared with the two criteria, typhoon Nuri is a typical typhoon.

Figure 3(c) shows wind speed and direction during typhoon Hagupit. It can be seen that the wind direction altered $120^{\circ}$ in the clockwise direction with the wind speed over 8 th grade Beaufort scale. The significant " $\mathrm{M}-$-" shaped bimodal distribution was found, and the minimum value of wind speed between two peaks was $11.9 \mathrm{~m} / \mathrm{s}$, and the maximum value of the whole typhoon was $45.9 \mathrm{~m} / \mathrm{s}$. All of the characteristics of the wind speed and direction well satisfied the two criteria mentioned above in Section 2, suggesting that typhoon Hagupit is also a typical typhoon.

3.2. Drag Coefficient during Strong Typhoons. The drag coefficient is found directly by evaluating the ratio of the friction velocity and the mean wind speed difference squared as follows:

$$
C_{d}=\left(\frac{u_{*}}{U}\right)^{2}
$$



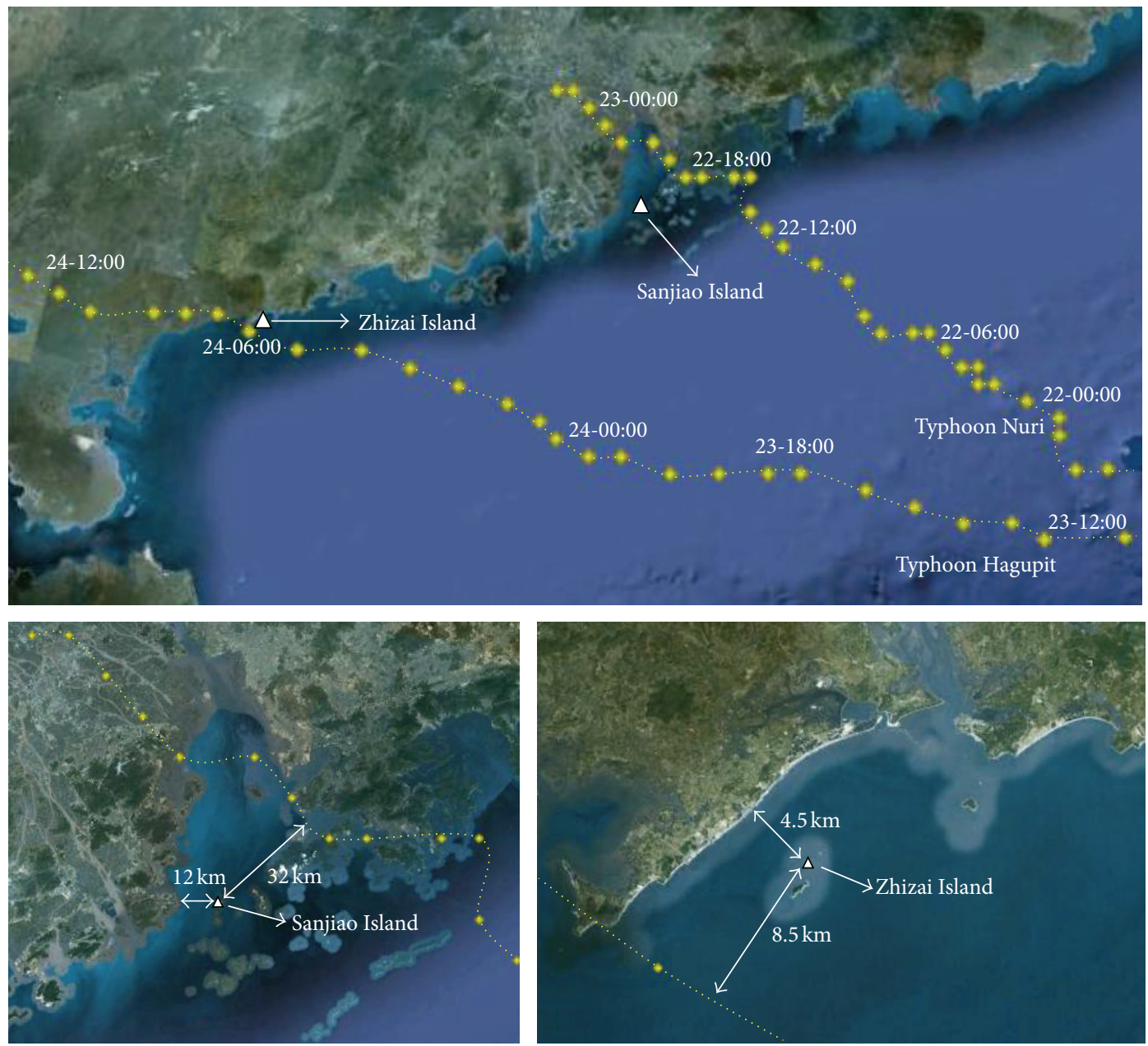

FIGURE 1: Typhoon tracks (yellow dotted lines) and positions of the observation sites Zhizai Island and Sanjiao Island. The distance between northeastern coast of Macao and the Sanjiao Island is about $12 \mathrm{~km}$, and the shortest distance between the $100 \mathrm{~m}$ high observation tower sites at Zhizai Island and the coast is $4.5 \mathrm{~km}$. The center of typhoon Nuri passed the tower at 18:50 on August 22, 2008, and the shortest distance from Sanjiao Island to typhoon center is about $32 \mathrm{~km}$. The center of typhoon Hagupit passed the tower at 05:10 on September 24, 2008, and the shortest distance from Zhizai Island to typhoon center is about $8.5 \mathrm{~km}$.

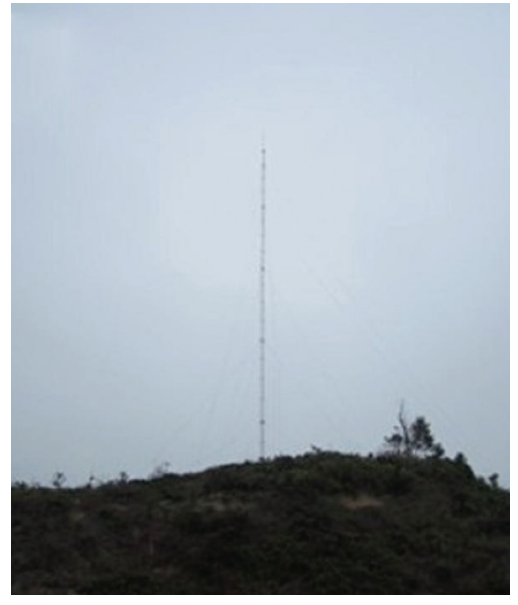

(a)

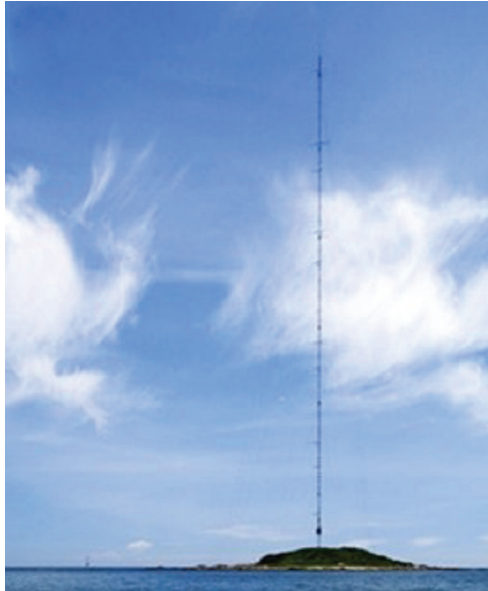

(b)

FIGURE 2: Sites of wind tower: (a) Sanjiao Island (where typhoon Nuri was observed) and (b) Zhizai Island (where typhoon Hagupit was observed). 


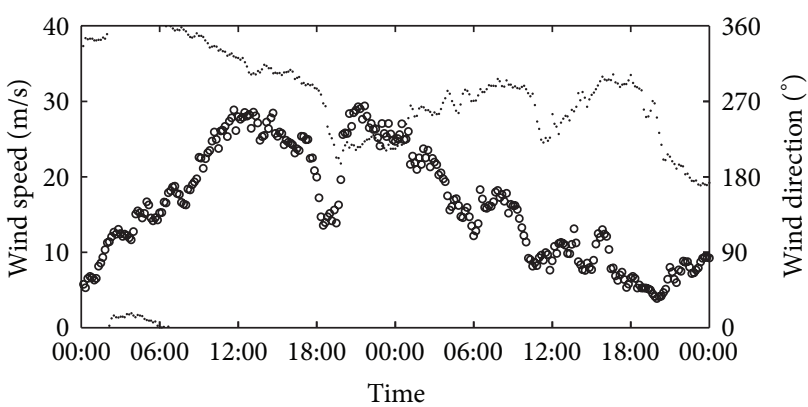

(a)

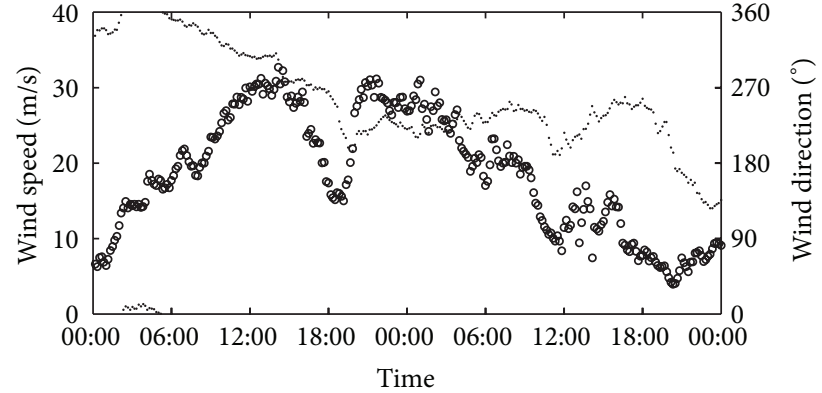

(b)

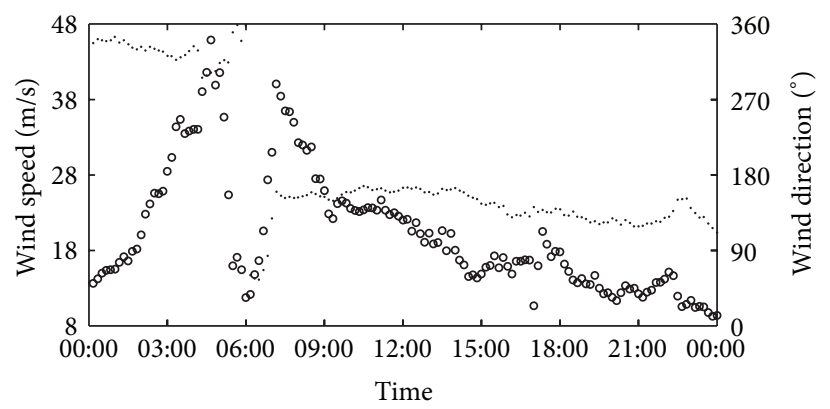

- Wind speed

- Wind direction

(c)

Figure 3: Wind speed and wind direction during strong typhoons: (a) typhoon Nuri from 00:00 am on August 22 to 23:59 pm on August 23, 2008, at $10 \mathrm{~m}$ height, (b) typhoon Nuri from 00:00 am on August 22 to 23:59 pm on August 23, 2008, at $60 \mathrm{~m}$ height, and (c) typhoon Hagupit from 0:00 am to 23:59 pm on September 24, 2008, at $60 \mathrm{~m}$ height.

TABLE 1: Detailed information of the two typhoon observations.

\begin{tabular}{|c|c|c|c|c|}
\hline Observation site & Type of wind & Wind direction & Elevation of the observation site & Area of the observation site \\
\hline \multirow{2}{*}{ Sanjiao Island (Nuri) } & Offshore wind & $0-75^{\circ}, 270-360^{\circ}$ & \multirow{2}{*}{$93 \mathrm{~m}$} & \multirow{2}{*}{$0.62 \mathrm{~km}^{2}$} \\
\hline & Onshore wind & $75-225^{\circ}$ & & \\
\hline \multirow[t]{2}{*}{ Zhizai Island (Hagupit) } & Offshore wind & $0-75^{\circ}, 225-360^{\circ}$ & \multirow[t]{2}{*}{$10 \mathrm{~m}$} & \multirow[t]{2}{*}{$0.0036 \mathrm{~km}^{2}$} \\
\hline & Onshore wind & $75-225^{\circ}$ & & \\
\hline
\end{tabular}

where $u_{*}$ represents the friction velocity calculated from the flux data using the relation

$$
u_{*}=\left({\overline{u^{\prime} w^{\prime}}}^{2}+{\overline{v^{\prime} w^{\prime}}}^{2}\right)^{1 / 4}
$$

and $U$ is 10 -minute average wind speed.

Figure 4 shows drag coefficient during typhoon Nuri. In general, drag coefficients were different at different heights, but the variation trends with time were similar. Before typhoon center passed, drag coefficients at $10 \mathrm{~m}$ height were greater than that of $60 \mathrm{~m}$ height. When typhoon center passed the wind tower, increments of drag coefficient at the two heights were observed, due to the low wind speed in typhoon eye region. After typhoon center passed, drag coefficients at the two heights made little difference.

Figure 5 shows drag coefficient during typhoon Hagupit. Before the typhoon center passed, there was a peak value (0.0050) of the drag coefficient at 4:10. An hour after the typhoon center passed, the greatest drag coefficient appeared, with a value of 0.0234 . During the period from 4:10 to 7:00, the drag coefficients changed dramatically, which may be resulted from low wind speed in typhoon eye region.

3.3. Variations of Drag Coefficient with Atmospheric Stability. The use of sonic data made it possible to calculate atmospheric stability by the fowling formula:

$$
\varsigma=\frac{z}{L}=-\frac{k z g\left(\overline{w^{\prime} \theta_{v}^{\prime}}\right)}{\overline{\theta_{v}} u_{*}^{3}},
$$

where $\varsigma$ is atmospheric stability, $z$ is height, and $L$ is the Monin-Obukhov length. The von Karman constant $k=0.4$ and the Gravitational acceleration $g=9.8 . \bar{\theta}_{v}$ is virtual potential temperature, $w$ is vertical wind speed, and $u_{*}$ is friction velocity.

Figure 6 is the atmospheric stability during typhoons Nuri and Hagupit. In order to compare atmospheric stability 


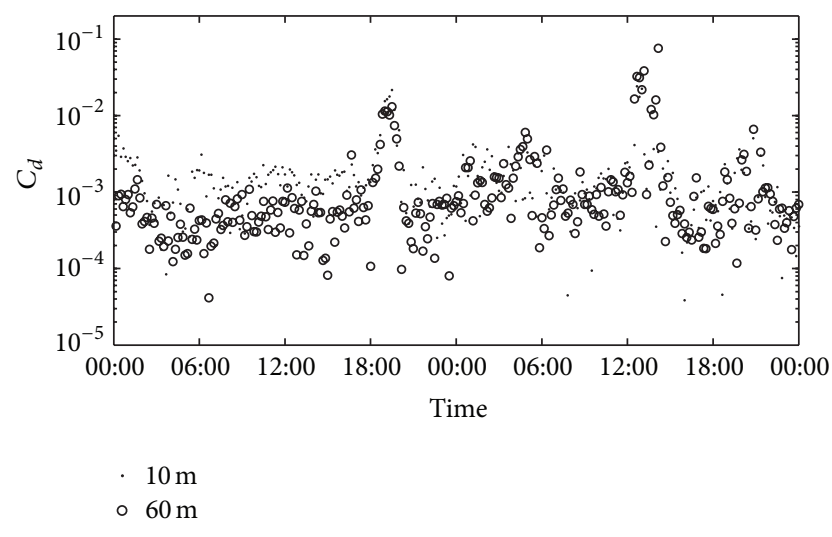

FIgURE 4: Drag coefficients during typhoon Nuri from 00:00 am on August 22 to 23:59 pm on August 23, 2008, at $10 \mathrm{~m}$ and $60 \mathrm{~m}$ height.

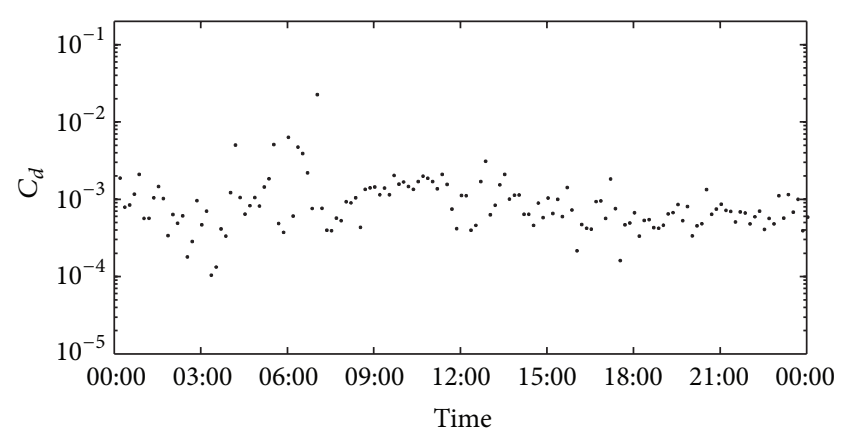

Figure 5: Drag coefficients during typhoon Hagupit from 0:00 am to $23: 59 \mathrm{pm}$ on September 24, 2008, at $60 \mathrm{~m}$ height.

between different typhoons before and after typhoon center passed, samples from 07:00 am on August 22 to $07: 00 \mathrm{am}$ on August 23, 2008, during typhoon Nuri were selected. During the period, the absolute values of atmospheric stability at $10 \mathrm{~m}$ height were close to zero, indicating the atmosphere stratification was nearly neutral. At $60 \mathrm{~m}$ height, the atmospheric stability varied from -2 to 2 , indicating weak stable or weak unstable stratification. Before typhoon eye passed the difference of atmospheric stability between $10 \mathrm{~m}$ and $60 \mathrm{~m}$ height it was small. As winds were from the land before typhoon center passed, the small difference between the two heights indicated that the influence of land surface on atmospheric stability was similar at different heights. After typhoon center passed, atmospheric stability of most samples at $10 \mathrm{~m}$ height was greater than zero, while at $60 \mathrm{~m}$ height was smaller than zero. After typhoon center passed, winds were from the sea, with the large difference of atmospheric stability indicating that the influences of the sea surface on atmospheric stability were different at different heights.

Figure 7 shows variations of drag coefficient with atmospheric stability in onshore direction during typhoons Nuri and Hagupit. During typhoon Nuri (Figure 7(a)), atmospheric conditions are different at different heights. At $10 \mathrm{~m}$ height, $\varsigma$ is greater than zero, and drag coefficient reduces regularly as atmospheric stratification changes from neutral to weakly stable. At $60 \mathrm{~m}$ height, $\varsigma$ is lower than zero, and drag coefficient reduces regularly as atmospheric stratification changes from neutral to weakly unstable. The curve which can describe the regular variation of drag coefficient was derived from these observation data as follows:

$$
C_{d}=\left\{\begin{array}{l}
\exp \left(0.8660 \varsigma^{2}+3.6106 \varsigma-6.0184\right), \\
\exp \left(13.0547 \varsigma^{2}-15.8059 \varsigma-5.9793\right) .
\end{array}\right.
$$

During typhoon Hagupit, variation of drag coefficient with atmospheric stability is not so regular like typhoon Nuri, and no relationship was found between drag coefficient and atmospheric stability during typhoon Hagupit.

\subsection{Variation of Drag Coefficient with Wind Speed in Onshore} Direction. The data pairs $\left(C_{d}, U\right)$ in onshore direction are graphically presented in Figure 8. In general, variation trends of drag coefficient with wind are similar for the two typhoons. It can also be seen that variation trends of drag coefficient with wind are accordant at different heights during typhoon Nuri. Drag coefficient increases until wind speed reaches a certain threshold and decreases when wind speed is greater than the threshold. For different typhoons, the thresholds are different. The threshold is about $15 \mathrm{~m} / \mathrm{s}$ for typhoon Nuri, $25 \mathrm{~m} / \mathrm{s}$ for typhoon Hagupit, and $40 \mathrm{~m} / \mathrm{s}$ for other researchers' [6].

During typhoon Nuri, drag coefficient assumes very large values in the onshore direction for the wind speed reaches about $25 \mathrm{~m} / \mathrm{s}$ at both $10 \mathrm{~m}$ and $60 \mathrm{~m}$ height. The relationship between drag coefficient and wind speed in onshore direction can be described by the following formulae:

$$
C_{d}= \begin{cases}10^{-3}\left(0.0284 U^{2}-3.9000 U+14.2000\right), & U \leq 15 \mathrm{~m} / \mathrm{s} \\ 10^{4} \times 8.4061 U^{-5.5597}, & U>15 \mathrm{~m} / \mathrm{s} .\end{cases}
$$

During typhoon Hagupit, drag coefficient ranges from 0.0007 to 0.003 . Drag coefficient increases slowly until wind speed reaches about $25 \mathrm{~m} / \mathrm{s}$. When wind speed is greater than $25 \mathrm{~m} / \mathrm{s}$, there are only several samples; nevertheless, it could be seen that drag coefficient decreases regularly with wind speed. A least squares analysis on the data pairs in onshore wind direction produced the following "best fit" regression equation:

$$
C_{d}= \begin{cases}10^{-3}\left(0.0063 U^{2}-0.1499 U+1.500\right), & U \leq 25 \mathrm{~m} / \mathrm{s}, \\ 3.0541 U^{-2.3837}, & U>25 \mathrm{~m} / \mathrm{s} .\end{cases}
$$

Figure 9 shows the average drag coefficient of typhoons Hagupit and Nuri in onshore direction. Here drag coefficients from different sites at the same height are compared. In the onshore direction at $60 \mathrm{~m}$ height, drag coefficient during typhoons Hagupit and Nuri makes some difference for different speed bins. In general, when wind speed is greater than $10 \mathrm{~m} / \mathrm{s}$ and lower than $25 \mathrm{~m} / \mathrm{s}$, drag coefficient of typhoon Nuri is far greater than that of typhoon Hagupit. When wind speed is greater than $25 \mathrm{~m} / \mathrm{s}$, drag coefficient of typhoon Nuri reaches the same order of magnitude as typhoon Hagupit. 


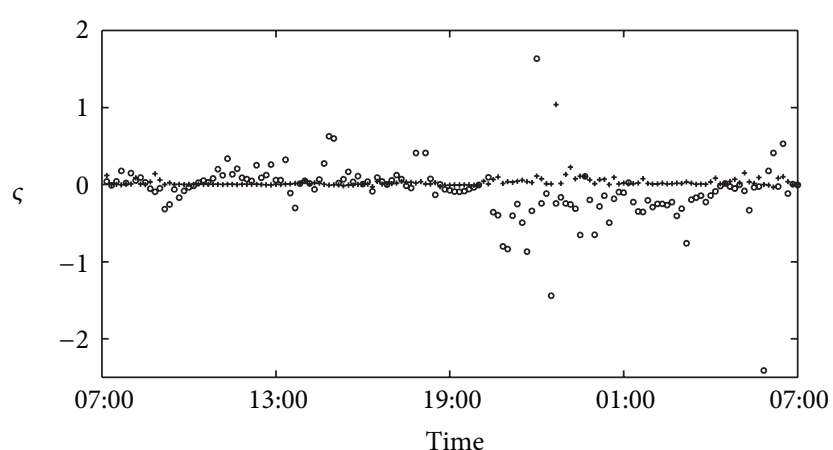

$+10 \mathrm{~m}$

$\circ 60 \mathrm{~m}$

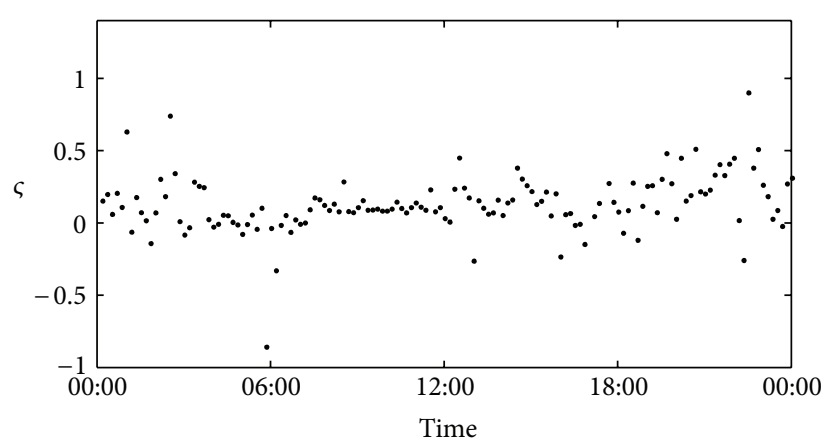

(b)

FIgURE 6: Atmospheric stability during strong typhoons: (a) typhoon Nuri from 00:00 am on August 22 to 23:59 pm on August 23, 2008, at $10 \mathrm{~m}$ and $60 \mathrm{~m}$ height and (b) typhoon Hagupit from 0:00 am to 23:59 pm on September 24, 2008, at $60 \mathrm{~m}$ height.

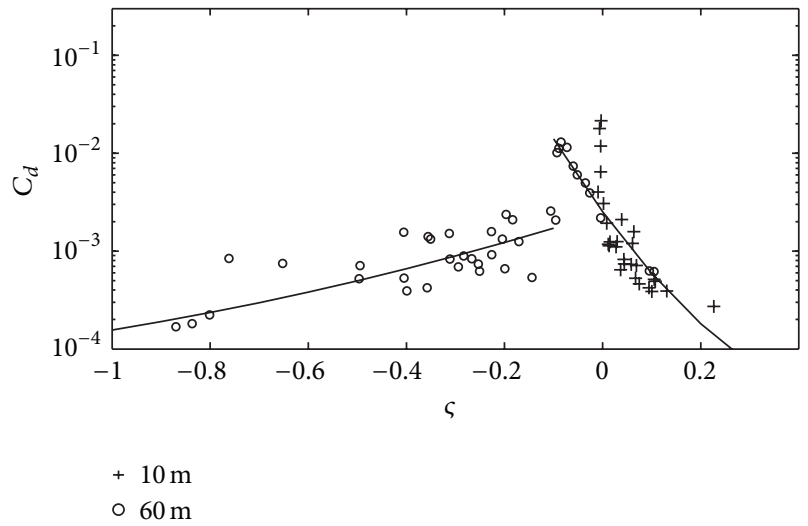

(a)

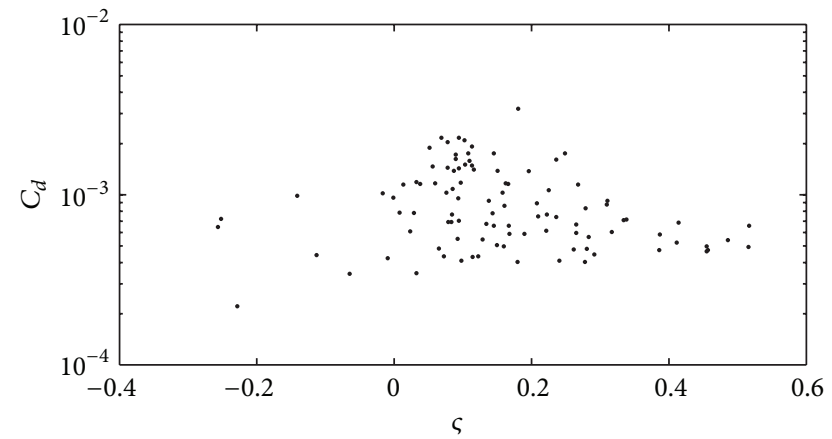

(b)

FIGURE 7: Variations of drag coefficient with atmospheric stability in onshore direction during strong typhoons: (a) typhoon Nuri at $10 \mathrm{~m}$ and $60 \mathrm{~m}$ height and (b) typhoon Hagupit at $60 \mathrm{~m}$ height.

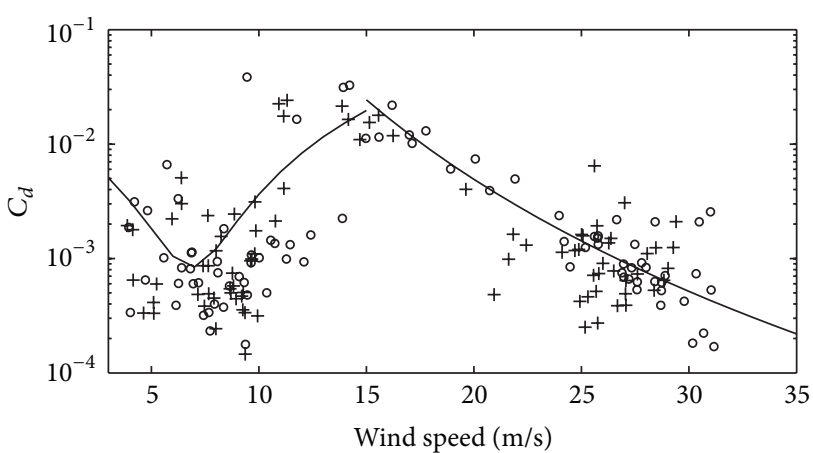

+ Nuri $10 \mathrm{~m}$

- Nuri $60 \mathrm{~m}$

(a)

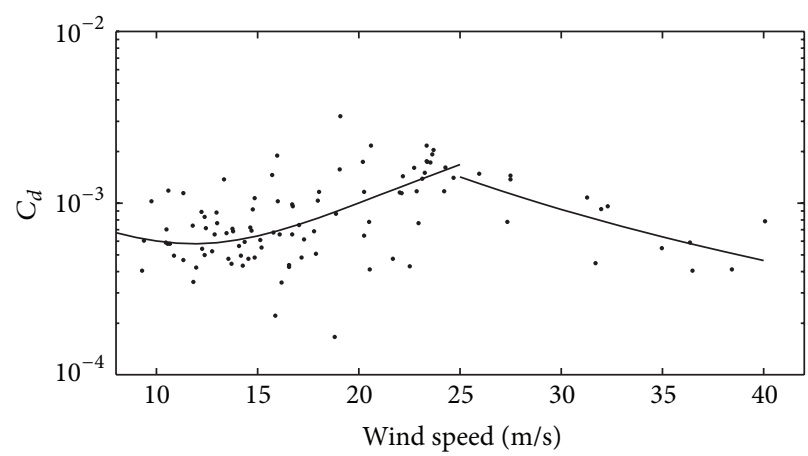

- Hagupit $60 \mathrm{~m}$

Figure 8: Drag coefficient as a function of wind speed during strong typhoons in onshore direction: (a) typhoon Nuri and (b) typhoon Hagupit. 


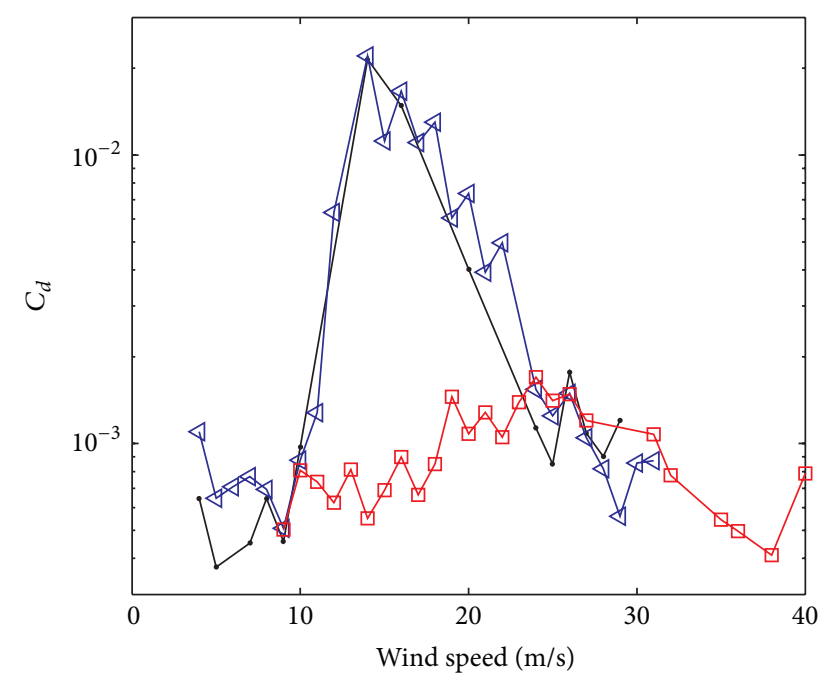

$\multimap$ Nuri $10 \mathrm{~m}$
$\neg \quad$ Nuri $60 \mathrm{~m}$
$\square \quad$ Hagupit $60 \mathrm{~m}$

FIGURE 9: Average drag coefficient of typhoons Hagupit and Nuri in onshore direction, and the wind speed bin is $1 \mathrm{~m} / \mathrm{s}$.

By comparing drag coefficients at the two heights during typhoon Nuri, it can be found that the relationships between drag coefficient and wind speed are similar at different heights.

Another fact which is worth noting is that wind thresholds for typhoon Nuri and typhoon Hagupit are different from other researchers' result [6]. It is maybe resulted from different observation sites. Typhoon Nuri was observed from a tower located on a 93-meter high hill, while typhoon Hagupit was observed from a tower located on a 10-meter high hill. Furthermore, Sanjiao Island where typhoon Nuri was observed covers an area of $0.62 \mathrm{~km}^{2}$, while Zhizai Island only covers an area of $0.0036 \mathrm{~km}^{2}$. The average distance from the tower to the edge of Sanjiao Island is about $840 \mathrm{~m}$ and to Zhizai Island is about $45 \mathrm{~m}$ in the onshore direction. Winds from the onshore direction are mainly affected by the sea surface but are also influenced by the land where the tower is located. These observation environments make the sea surface roughness length, arisen from wave or other factors from open sea surface produce lesser effect on drag coefficient during typhoon Nuri. That is to say, relationships between drag coefficient and wind speed derived from typhoon Nuri and typhoon Hagupit are not from real open sea surface. Powell et al's [6] experiment was conducted in open sea, and was not affected by land. These different observation sites may be why the wind thresholds are different for different typhoons. Consequently, whether the observation data are affected by land may be a key factor which determines the threshold. Considering other researchers' experiments from open sea and these experiments from islands in this work, it can be concluded that the larger area of the land where observation data are collected is responsible for the lower threshold of wind speed.
3.5. Variation of Drag Coefficient with Wind Speed in Offshore Direction. Figure 10 shows the variation of drag coefficient with wind speed during typhoons Nuri and Hagupit in offshore direction. It can be seen that drag coefficient fluctuates obviously from 0.0001 to 0.001 during typhoons Nuri and Hagupit, and no regular relationship is found between drag coefficient and wind speed. It may be resulted from the distance from the observation tower to shore and complex land surface in offshore direction.

\section{Conclusion}

Using data from wind towers during typhoons Hagupit and Nuri, drag coefficient was estimated. The relationship between drag coefficient and atmospheric stability was examined, finding that the drag coefficient decreased when atmosphere stability changed from weakly stable or unstable to neutral. Relationship between drag coefficient and wind speed was also examined, and the result indicated that the relationships between drag coefficient and wind speed were similar to other researcher's result, but the wind thresholds were different due to different observation sites. Some preliminary conclusions are obtained as follows.

(1) By comparing atmospheric stability at the two heights during typhoon Nuri in onshore direction, it is found that atmospheric conditions are different at different heights. At $10 \mathrm{~m}$ height, $\varsigma>0$, and drag coefficient reduces regularly as atmospheric stratification changes from neutral to weakly stable. At $60 \mathrm{~m}$ height, $\varsigma<0$, and drag coefficient reduces regularly as atmospheric stratification changes from neutral to unstable. The curve which can describe the regular variation of drag coefficient is derived from these observation data as follows:

$$
C_{d}=\left\{\begin{array}{l}
\exp \left(0.8660 \varsigma^{2}+3.6106 \varsigma-6.0184\right) \\
\exp \left(13.0547 \varsigma^{2}-15.8059 \varsigma-5.9793\right)
\end{array}\right.
$$

(2) In onshore direction at $60 \mathrm{~m}$ height, drag coefficient during typhoons Hagupit and Nuri makes some difference for different speed. In general, when wind speed is greater than $10 \mathrm{~m} / \mathrm{s}$ and lower than $25 \mathrm{~m} / \mathrm{s}$, drag coefficient of typhoon Nuri is far greater than that of typhoon Hagupit. When wind speed is greater than $25 \mathrm{~m} / \mathrm{s}$, drag coefficient of typhoon Nuri reaches the same order of magnitude as typhoon Hagupit. By comparing drag coefficients at the two heights during typhoon Nuri, it can be found that the relationships between drag coefficient and wind speed are similar at different heights.

(3) In onshore direction, relationships between drag coefficient and wind speed are derived from observation data of different typhoon cases, showing considerable difference between different typhoons.

During typhoon Nuri, the relationships between drag coefficient and wind speed are similar at $10 \mathrm{~m}$ and $60 \mathrm{~m}$ height:

$$
C_{d}= \begin{cases}10^{-3}\left(0.0284 U^{2}-3.9000 U+14.2000\right), & U \leq 15 \mathrm{~m} / \mathrm{s}, \\ 10^{4} \times 8.4061 U^{-5.5597}, & U>15 \mathrm{~m} / \mathrm{s} .\end{cases}
$$




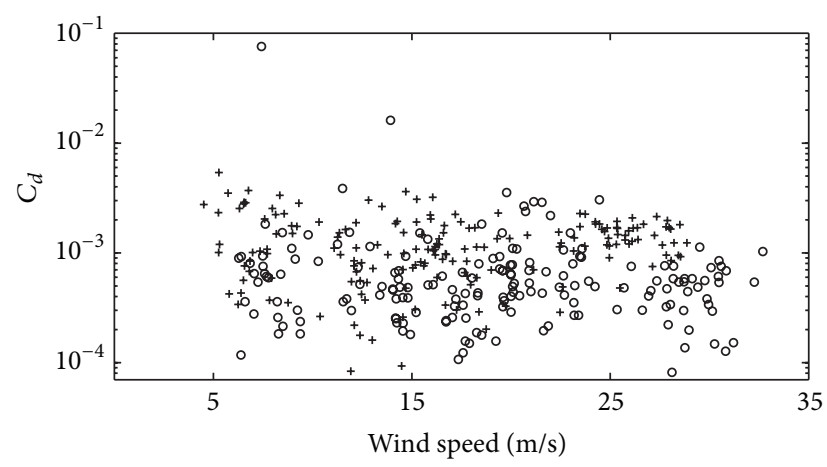

+ Nuri $10 \mathrm{~m}$

○ Nuri $60 \mathrm{~m}$

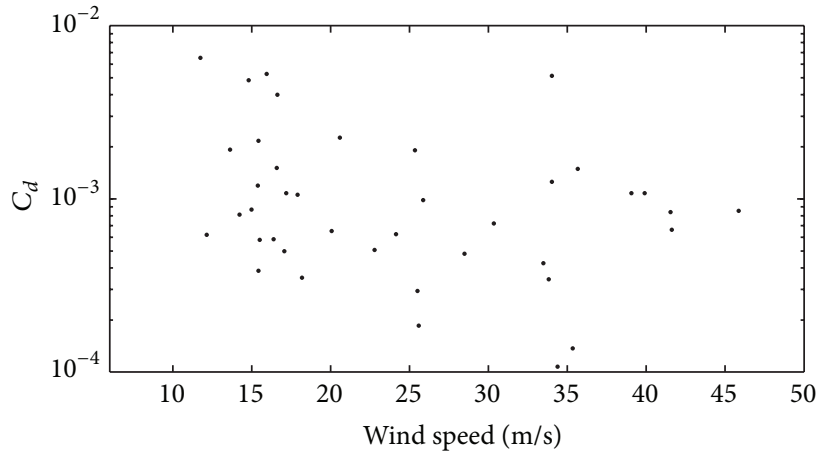

- Hagupit $60 \mathrm{~m}$

(a)

(b)

FIGURE 10: Variation of drag coefficient with wind speed during strong typhoons in offshore direction: (a) typhoon Nuri and (b) typhoon Hagupit.

During typhoon Hagupit at $60 \mathrm{~m}$ height,

$$
C_{d}= \begin{cases}10^{-3}\left(0.0063 U^{2}-0.1499 U+1.500\right), & U \leq 25 \mathrm{~m} / \mathrm{s} \\ 3.0541 U^{-2.3837}, & U>25 \mathrm{~m} / \mathrm{s}\end{cases}
$$

Considering the same expression of typhoon Nuri at different height, the relationship at $60 \mathrm{~m}$ height during typhoon Hagupit can be thought to work at $10 \mathrm{~m}$ height.

(4) Variation trends of drag coefficient with wind in this work are similar to other researcher's result, but the wind thresholds are different. Whether the observation data are affected by land may be a key factor which determines the threshold. Considering other researchers' experiments from open sea and these experiments from islands in this work, it can be concluded that the larger area of the land where observation data are collected is responsible for the lower threshold of wind speed. Here, the wind threshold is a value. Drag coefficient increases until wind speed reaches a certain threshold and decreases when wind speed is greater than the threshold.

\section{Acknowledgments}

The comments of the two referees are gratefully acknowledged. This material is supported by the National Natural Science Foundation of China (Grant no. 91215302), the Clean development mechanism Foundation (Grant no. 1212014), and National Department Public Benefit Research Foundation (Grant no. GYHY201006035).

\section{References}

[1] C. Guan and L. Xie, "On the linear parameterization of drag coefficient over sea surface," Journal of Physical Oceanography, vol. 34, no. 12, pp. 2847-2851, 2004.

[2] G. L. Geernaert, K. B. Katsaros, and K. Richter, "Variation of the drag coefficient and its dependence on sea state," Journal of Geophysical Research, vol. 91, no. C6, pp. 7667-7679, 1986.
[3] K. G. Rao, "Roughness length and drag coefficient at two MONTBLEX-90 tower stations," Journal of Earth System Science, vol. 105, no. 3, pp. 273-287, 1996.

[4] A. A. Grachev, C. W. Fairall, and S. E. Larsen, "On the determination of the neutral drag coefficient in the convective boundary layer," Boundary-Layer Meteorology, vol. 86, no. 2, pp. 257-278, 1998.

[5] L. Mahrt, D. Vickers, J. Sun et al., "Determination of the surface drag coefficient," Boundary-Layer Meteorology, vol. 99, no. 2, pp. 249-276, 2001.

[6] M. D. Powell, P. J. Vickery, and T. A. Reinhold, "Reduced drag coefficient for high wind speeds in tropical cyclones," Nature, vol. 422, no. 6929, pp. 279-283, 2003.

[7] I.-J. Moon, I. Ginis, and T. Hara, "Effect of surface waves on airsea momentum exchange. Part II: behavior of drag coefficient under tropical cyclones," Journal of the Atmospheric Sciences, vol. 61, no. 19, pp. 2334-2348, 2004.

[8] V. K. Makin, "A note on the drag of the sea surface at hurricane winds," Boundary-Layer Meteorology, vol. 115, no. 1, pp. 169-176, 2005.

[9] L. L. Song, J. B. Pang, C. L. Jiang et al., "Field measurement and analysis of turbulence coherence for Typhoon Nuri at Macao Friendship Bridge," Science China Technological Sciences, vol. 53, pp. 2647-2657, 2010.

[10] R. S. Chen, Typhoon (in Chinese), Fujian Science \& Technology Press, Fujian, China, 2002.

[11] B. Wang, F. Hu, and X. Cheng, "Wind gust and turbulence statistics of typhoons in South China," Acta Meteorologica Sinica, vol. 25, no. 1, pp. 113-127, 2011.

[12] J. Højstrup, “A statistical data screening procedure," Measurement Science and Technology, vol. 4, no. 2, pp. 153-157, 1993.

[13] D. Vickers and L. Mahrt, "Quality control and flux sampling problems for tower and aircraft data," Journal of Atmospheric and Oceanic Technology, vol. 14, no. 3, pp. 512-526, 1997. 

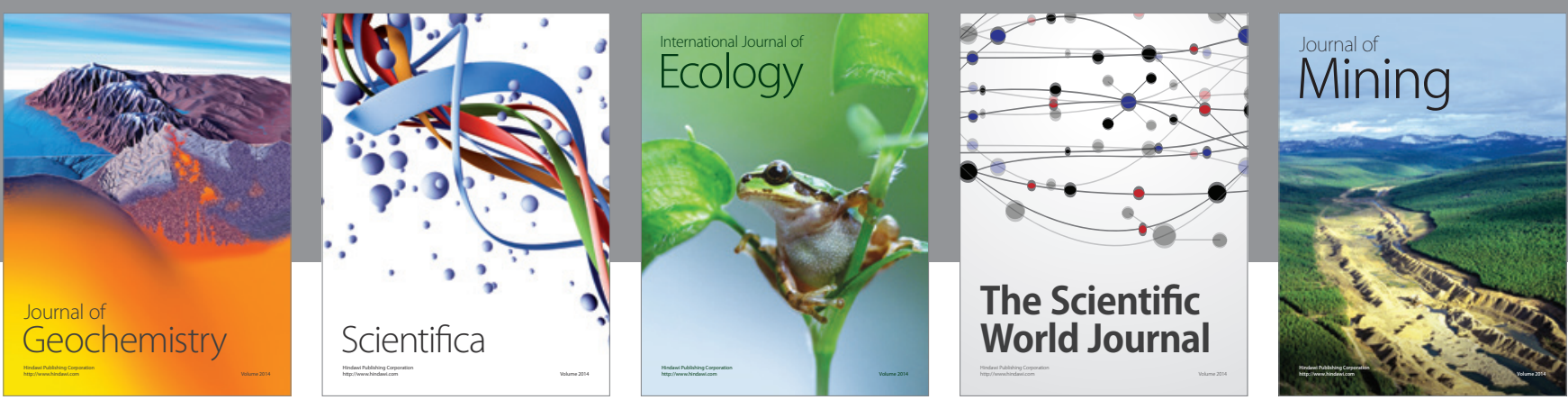

The Scientific World Journal
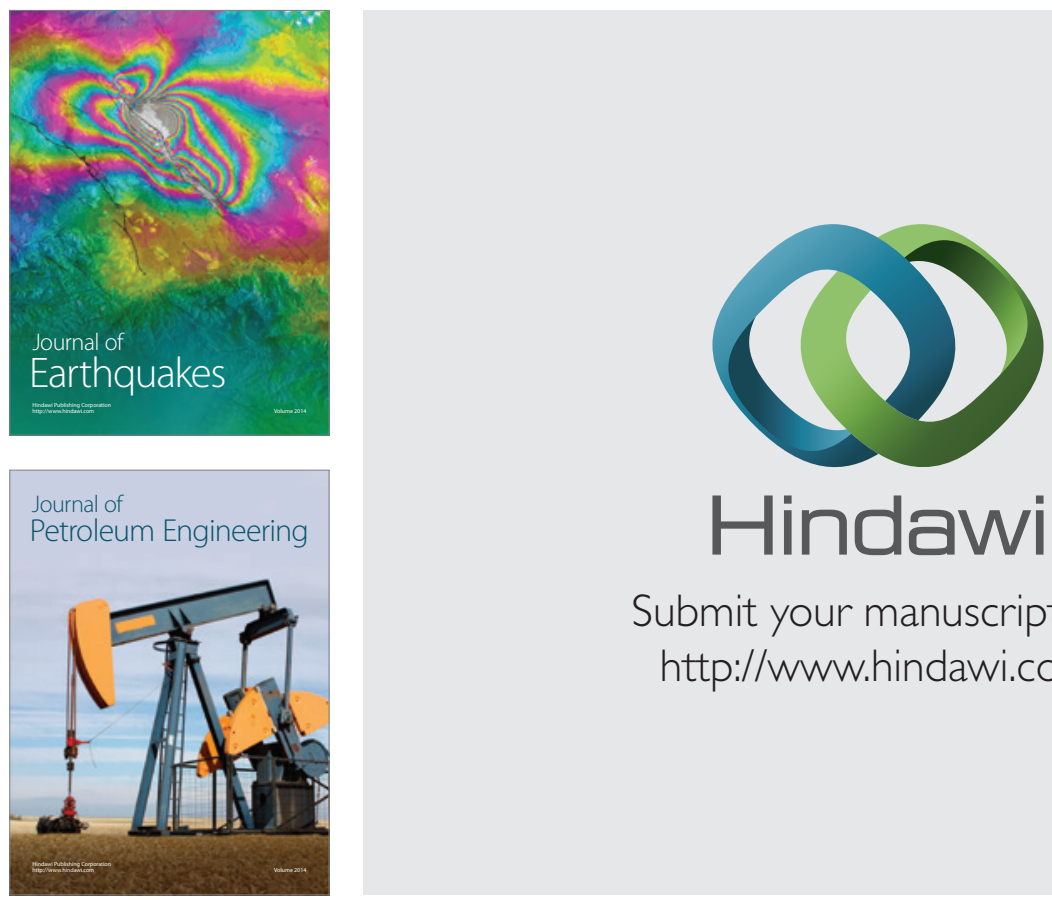

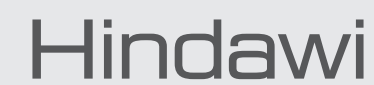

Submit your manuscripts at

http://www.hindawi.com
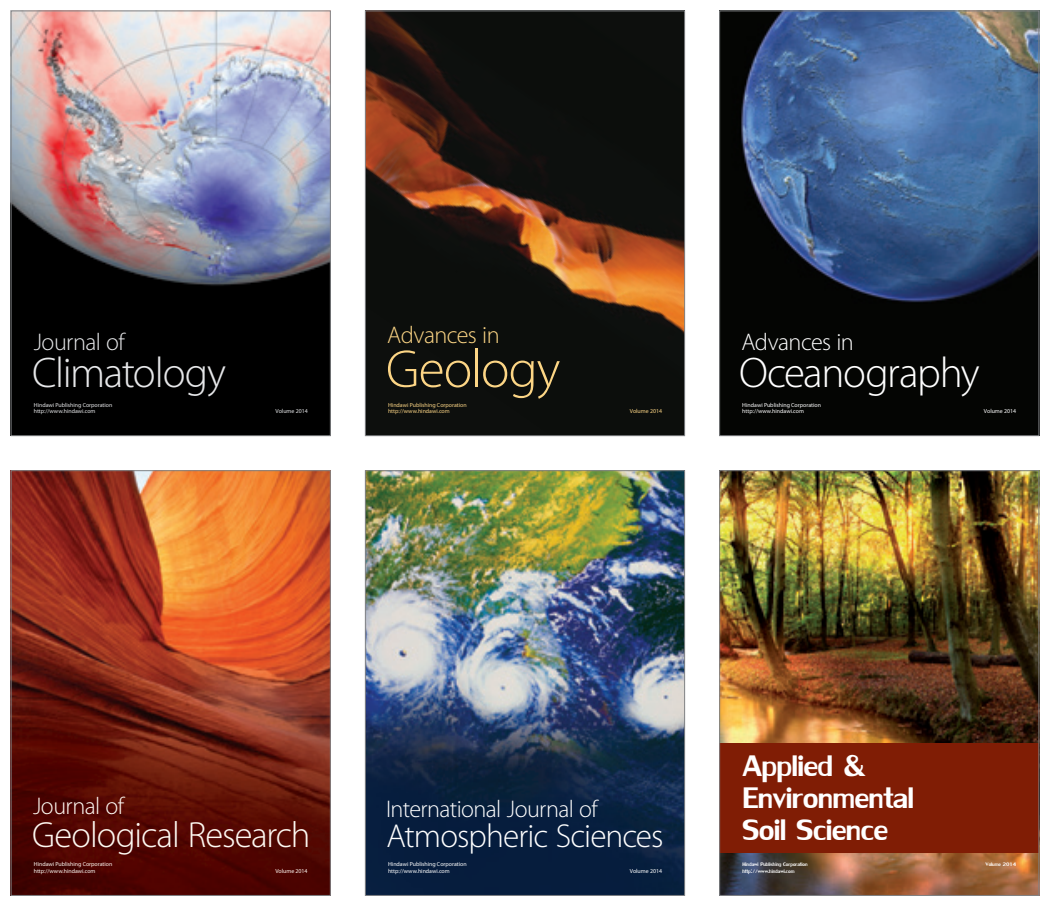
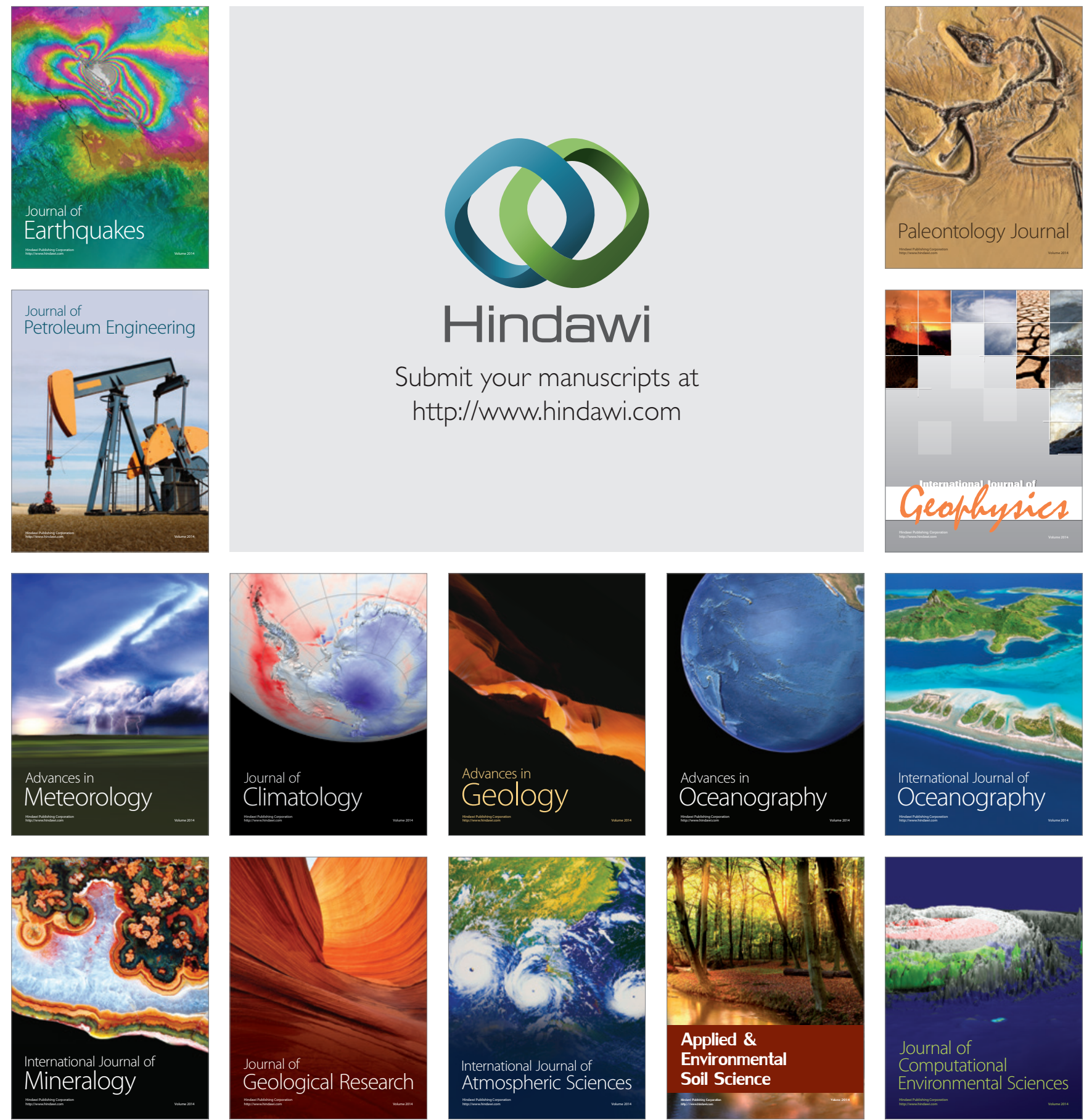